\title{
Attempting the Impossible: A Plea for Legal Economy
}

\author{
A. N. Allott*
}

\section{Impossible attempts}

This is not, I hasten to warn readers interested in criminal law, yet another examination of the law governing impossible attempts; though criminal law comes into the discussion. My theme is directed to the same set of problems which I canvassed in my Limits of Law (1980), ${ }^{1}$ that is, it concerns the limits on effectiveness and utility which are necessarily implied in the enterprise of regulating human conduct by law. Regrettably, one is obliged to note that there is no progress at all to report in reducing the weight and burden of legislation in the decade since the appearance of that work. In fact, things are getting steadily worse, as I shall seek to show.

Although this topic sounds theoretical and more in the realm of jurisprudence than of practical affairs, this impression would be totally wrong. The implications of this enquiry are deeply practical. What governments and those who push or pressure them are trying to do, viz. to multiply laws in the vain attempt to control whether by prescription or proscription - ever-increasing areas of our life in society, is doomed to partial or total failure. The failure becomes the likelier the heavier the weight of the new laws and their administration that is imposed on the society and its agents. We are, in my view, now reaching saturation point and beyond.

\section{Legal economy}

So much for attempting the impossible. Now for legal economy. I confess without shame that this is a pun. Often the truth lies in paronomasia. What is argued here is not just a study of the relations of law and economics, interesting and important though these are. But, just as we have the separate subjects of study represented by the terms 'politics' and 'economics' and yet find a need for a discipline linking them, which we call 'political economy', so in my view we should recognise, define, and operate within a new area of study, to be called 'legal economy'. This would provide more than a cost-benefit analysis (though that would form part of the concerns of the legal economist) of new and existing law; in

*Professor of African and Comparative Law, University of Buckingham.

1. Butterworths, London 1980, passim. 
this it would go beyond the impact and effectiveness studies which are currently in play. It would seek to provide a strategic overview of law-making, in comparison with what one may term the tactical studies so far made.

\section{Options}

It will do this first by looking at options. If politics is about choices, then controlling people's behaviour by a variety of means is a question of options. One may immediately indicate the possible range of such options which are available to a would-be regulator. Although - and this is one of the major criticisms to be developed in this paper - the legislative option, using law as the regulating mechanism, often springs first to mind, it is by no means the only, or even the most useful and effective, option. Confronted by behaviour of which he or she either approves or disapproves, or about which he or she is neutral, the regulator has a variety of options of which the first is the simplest, viz.:-

(i) The 'Liberty Hall' or 'hands-off' option. This is a very attractive option. It consists in doing nothing and spending nothing, whether of time or resources, on attempting to regulate or provide for the conduct in question. But, and this cannot be stressed too strongly, there may be consequential costs of a do-nothing policy, which are conveniently ignored at the time, but which must be brought into the reckoning on any cost-benefit appraisal of the societal situation as it develops.

(ii) The market option. This is a sophisticated variant of the hands-off option, involving the leaving of outcomes to the interplay of market forces. It differs from the hands-off, do-nothing approach in that it purports to be positive and intentional rather than negative in character, the hidden hand of the market being seen as promoting (ultimately) the survival of the fittest and the most economical and effective solution to the problem, whatever it may be.

(iii) The persuasive option. No use is made of administrative or legal structures to ensure a particular outcome; instead, a campaign of information and persuasion is undertaken by the government or under its impetus, intended to persuade people to behave in the fashion approved by the government of the day.

(iv) The physical option. Instead of seeking to achieve a result by one of the other means - viz. by persuasion, administrative action or law - physical means are used to achieve the desired result. The simplest example is the so-called 'sleeping policeman' or speed-ridge: persuasion or law or the pressure of traffic might be used to reduce and control vehicle speeds; the speed-ridge provides an alternative by interposing a physical obstacle to excessive speed.

(v) The administrative option. Without making the law the ultimate instrument of policy, the end sought is to be achieved by administrative action, within a legal framework usually, but relying essentially on policy and discretion.

(vi) The legal option. The making or adoption of a formal law to command, prohibit, or regulate the approved behaviour. This is or should be very much the last resort in the order of things, other options being pursued for preference with the appropriate action or inaction. 
It would not be accurate to say that it is only in the 20th century that the administrative and legal options have been used as the principal instruments of government policy: the history of previous centuries in many countries demonstrates the contrary. Think, for instance, of the sumptuary laws of ancient Rome, which embodied a governmental objective - the reduction of luxury which was achieved in post-war socialist Britain by penal rates of income tax, capital taxes, and purchase tax on luxury items. Think of Henry VIII and his attempts and those of his successors on the throne to impose religious conformity or right thinking and practice on his subjects by way of penal sanctions, which in the ultimate might include death; and contrast this with similar attempts to impose state-directed uniformity of thought and practice through the laws and machinery proscribing racial discrimination (though fortunately without such extreme sanctions for non-conformity!). The examples could be multiplied endlessly. But what is different about post-war Britain is the sheer volume or weight of laws and administrative machinery which have been used to promote governmental ends. Never before in human history have so many, and so complex, laws been accumulated in the pursuit of government policy.

It is not unexpected that resort to law is strictly limited in the societies which lacked or lack writing, which is to say, in the majority of human societies for most of human history. In such societies customary laws are the norm. Such laws, even when supplemented by chiefly or royal edict, have certain characteristics which tell against excessive law-making. The first feature of such laws is that they are oral, that is spoken, in character, and are recorded in the memories of men rather than in legal texts. Human memory, however powerful in pre-literate society, can only retain a certain amount of detail and complexity. Next, in so far as the law is customary, it is based on the habitual practices of the people; this implies that law is generated largely from the bottom-up rather than from the top-down, and represents the aspirations and attitudes of the law-subjects rather than those of their rulers. Further, the total quantity of law is restrained by the built-in obsolescence of customary laws. A written text endures over time; it is in principle permanent. English law subscribes to the principle that enacted laws are not repealed by mere lapse of time (this principle is falsified in practice, but no matter for the present argument). Contrary to the perceptions of some outside critics and observers of customary law, who tend to think that customary laws are by their history and nature fixed and unchangeable from generation to generation, actual study of such laws shows that in reality they can rapidly evolve, gaining features and losing features through the adoption of new practices or the abandonment of old ones. Finally, it goes without saying that the technology and social and physical demands of the society and its environment are much less extensive in simpler societies - that is why we call them 'simple'. But this adjective should not deceive us into failing to recognise that such societies - however crude their technical achievements - often exhibit elaborations of social behaviour and religious observance which are at least as complex as any in modern western countries. 


\section{The record so far}

It would be quite impossible to examine in detail the total reckoning of success or otherwise in the English attempt to regulate conduct by law. For a start, how do you measure success? (I consider some possible ways of evaluating the success of law below.) Furthermore, the examples of the use of law to promote social or political ends are now so numerous - that is one of the complaints! - that a bare but typical selection must do.

First, let us consider the road traffic laws. Two items must be enough for present purposes. First, total failure. The speeds of motor vehicles on every road in this country are now purportedly regulated, in the interests of safety, by speed limits imposed by or under law. Do vehicles systematically drive at or below these limits? In central London they usually do, but this is not because of the law but because the overwhelming pressure of traffic prevents their going as fast as carriages and carts went in the horse-drawn era. In built-up areas otherwise, the $30 \mathrm{mph}$ limit is usually respected only by the very elderly, learner drivers, some magistrates, and cars being immediately followed by a police vehicle. Go out into the country and onto the motorways, and the situation is much worse. A qualitative but effective method of measuring compliance with the $70 \mathrm{mph}$ limit is to drive exactly at 70 mph in the 'slow' lane and see how many vehicles pass one, and how many one passes. When, to the annoyance of other road-users, I have carried out this experiment, 10 cars pass me for every car I pass. The police authorities, recognising the impossibility of enforcing these limits, have created one of their own: in exercising their statutory control over prosecutions, they have announced, they will not prosecute motorists going less than 85 but more than 70 . This can hardly be adduced as a sign of the effectiveness of the law; rather, it testifies to the power of law-subjects to modify the law in action by their own systematic non-compliance.

Next, an unexpected success. Before the law provided for the wearing of seat-belts by front-seat passengers and drivers was brought into effect, I shared the general scepticism that this law, which was said to infringe fundamental personal liberties as well as being impossible to enforce, would be unenforced and disregarded in practice. This scepticism was misplaced, as events turned out, even though prosecutions for not wearing a belt are rare. Figures from the Department of Transport, as well as my own personal systematic observations on selected roads, indicate that more than $90 \%$ of drivers now habitually wear their belts. (Strangely enough the city with the lowest score, under $90 \%$, is Belfast. Perhaps compliance with the law generally has decreased there; or maybe breaking this law is part of a process of releasing oneself from the stresses imposed by other law-breakers?) Why the law on speed fails, while that on seat-belts succeeds, is difficult to say; but an attempt is made below to answer this question when the factors which make for successful regulation of conduct are looked at.

Next, we may take the Data Protection Act 1984 as an example of a regulatory law of the modern type, of which many more are promised or threatened. A problem is 
identified - in this case, the possible misuse of information about individuals stored in computer memories. To tackle this problem, an enormous apparatus of regulation has to be set up, supported by criminal sanctions against those who do not observe the requirements. So we must have registrars, returns, access regulations, codes of practice, and all the rest of the administrative framework. So onerous are the requirements, and so inadequate the machinery and personnel available to oversee them, that one could make the confident prediction that there would be large-scale non-compliance, as much due to ignorance as to wilfulness. In the nature of things it is impossible to put a number on the percentage of non-compliance. Anecdotally, especially as it concerns small businesses and data-users, it appears that failure to conform is widespread, and - what is more important - impossible to detect or remedy.

\section{Measuring success}

All laws are ostensibly passed to achieve some goal or goals. There are those who object that it is impossible to spell out the purposes of any law, and so one cannot decide whether any given law achieves its purposes, and so can be counted as a success. With unenacted laws, this is because, they aver, the legal rules have no known source. This is obviously so for customary legal rules, which are formed on the basis of the habitual practices of the people subject to them, and are recognised as having binding force over their subjects (but even this presentation ignores the contribution made by those who decide cases to the articulation and approval of particular rules as rules of law). That unenacted law has no source, and hence no intrinsic purpose, is less obviously so in the case of judge-made law, as one might argue that a given rule of, say, common law can be traced back to a particular judgment or judgments; the authors of these judgments can accordingly be esteemed to be the authors of the rules which their decisions embody (and farewell to the declaratory theory!). But this does not help us as much as we would wish English judges habitually fight shy of articulating the ultimate purposes which they seek to achieve through their formulation of the law in the given case. Instead, they emphasize that their job is restricted to deciding the case before them. Furthermore, it is notorious that the reason of a decision, the ratio, is not necessarily left as the judge deciding the precedent chose to formulate it; it may be reworked, or a completely new ratio substituted, by a later court interpreting and applying the precedent.

In the case of enacted law, the problems are different. So many fingers are in the legislative pie that one cannot definitively say which was responsible for inserting the purposive plum. How is one to decide, it is asked, whether to credit the draftsman, those who instruct him (the civil servants in their departments), the minister who puts forward the Bill to the House, or, finally, the members of each House of Parliament who discuss and decide on the text of the Act (or worse, those who are in the majority voting for any given provision)? The purposes of each person or group of persons might differ, or even be internally in conflict with each other. 
This would leave us with a law without purpose, explicit or implicit, however it is thought to be generated or discoverable. This - one must submit - is a contradiction in itself. Even if the purpose or purposes (and they are usually plural) of a given law or set of provisions may be difficult to isolate or may change from time to time, law as an enterprise presents itself to those subject to it as a purposeful, motivated set of communications. If I hear a voice on the village loudspeaker (as one might have done in Nazi-occupied Europe) telling the inhabitants to do or not to do something, I would assume that its instructions are obligatory, carry sanctions for non-compliance and have purposes, even if these are not known to me, and I do not know the identity of the person issuing the command or what is his juridical authority for so doing. In other words, what counts is the message at the point of sale or effect. Those issuing such messages may be presumed to have objectives and purposes which they seek to achieve. Laws, as human communication, carry within them purposes which we can try to discover and to use as measures of the effectiveness of the law, and it makes no difference if the purpose is an ex post facto reconstruction. In the case of the loudspeaker message, it might be declaring a curfew. The immediate purpose of this might be to keep the inhabitants in their houses at night. The presence of anyone on the streets after curfew time would be an indicator of partial failure of the order, and is in principle measurable. The ultimate purpose underlying the order might be to cut down on resistance activity.

On this analysis, one may distinguish between the immediate purposes of a law, and the ultimate objective which lies behind it. Thus the law on speed limits has as its immediate purpose to hold down vehicle speeds to a safe level. In doing this, it does not stand alone; the law on careless or dangerous driving also comes in to define what is a safe speed in all the circumstances of a given case. The ultimate objective of the law is to make driving safer for all who venture on the roads. This objective involves other factors and measures which are not necessarily legal, such as proper design and maintenance of roads, signposting, and driver training.

It follows that in evaluating the success of a law, one must have regard in the first place to how it satisfies its immediate purpose (in the speed limits case, to hold down speeds), and in the second place to how far this immediate purpose contributes to the ultimate objective (holding down vehicle speeds as a contribution to road safety).

Some of the simpler laws are amenable to easily qualified measures of success, at least so far as the immediate purpose of the law is concerned. But most laws are either too complex to be subjected to such a simple analysis, or are not capable of being appraised quantitatively. Qualitative measures are much vaguer and more subjective. Theoretically, for instance, one might measure the success of the anti-drug laws by the number of seizures of drugs being smuggled into this country; but since one has no idea what is the total quantity of such drugs being illegally imported it is impossible to state what is the percentage seized, and whether this is improving year-on-year. Nor indeed can one confidently say 
whether either the success or the failure of the law is attributable to the framing of the law itself, or to the quality and effectiveness with which it is administered. In the current debates (examples of which I mention later on) about the need for tougher or new laws to deal with this and that problem, this fundamental difficulty of appraisal is vital to devising a regulatory strategy. If one cannot say with confidence whether certain regulations are effective or not, how is one to decide which to choose, and which to vary? In the case of river pollution, for example, chemical analysis of rivers provides some gauge of success or failure of anti-pollution measures; in the case of child abuse there is no such gauge.

But there are limits to the quantitative approach to the measurement of legislative success. There is the problem, already adumbrated, of what inferences one can draw from raw quantitative data as to the compliance with, or effectiveness of, a given law. On the principle, familiar to computer programmers, of 'garbage in, garbage out', one cannot hope to extract more, and more reliable, information from the data which one inputs than the data themselves bear. In other words, can one rely on the relevant statistics? It was a common political quip in the $1960 \mathrm{~s}$, when the government was said to be operating with out-of-date economic statistics, that they were trying to run the railways according to last year's timetable. In our case, that of effectiveness of laws, doubt has been cast, not just on the timeliness of the statistics, but on whether they bear any resemblance to reality whatsoever. Two important surveys have just been published in this area, both directed to the same question: what is the relation between the reported and the actual incidence of crime? One of these surveys is the Islington Crime Survey, carried out in the relevant part of Inner London; the other is the latest official Home Office British Crime Survey, which reflects the incidence of criminality in 1987. Both surveys carry the same dismal and disappointing message: the incidence of crime is grossly under-reported (as little as one in four, or even fewer, crimes reported to the police). Planning for the criminal justice system, and attempts to assess its effectiveness, e.g. in reducing the quantity of burglary, are effectively impossible.

\section{Some current concerns where a legal reaction is demanded}

To measure how ingrained and automatic is the current obsession with law as the remedy for all ills, one cannot do better than take a single issue of a quality newspaper as offering a representative reflection of the community's immediate concerns and the remedies proposed. The Sunday Times issue of February 25th, 1989, which I have to hand, illustrates the point exactly. These topics include:-

(i) Blasphemy. In the wake of the Salman Rushdie affair, there are strong calls for the extension of the blasphemy laws to prevent injury to the religious feelings of Muslims, Hindus and Jews as well as of Christians (in other words, effectively making a new and comprehensive public order offence). Other commentators, without realising the implications of the proposal, have argued for a new offence of defaming a dead religious leader or prophet or teacher. Traducing the Buddha, 
Mahomed, Jesus Christ, or L. Ron Hubbard (and even the Ayatollah Khomeini himself) would be caught by such a law. Would this simultaneously mean a general extension of the law of civil or criminal libel to cover defamation of dead persons generally - of whatever religious significance? If so, it would put a stop to rude plays about Churchill, and also to most Hollywood or political autobiographies.

(ii) Pollution of rivers. The new Water Bill is criticised, as is the existing law, as providing inadequate control of polluters or penalties for them. New safeguards are called for, with heavier penalties, including the imprisonment of those in large companies who contribute to pollution.

(iii) Unfit food. Quite apart from the salmonella and listeria scares, we now have concern about substandard tinned food sold by food salvage companies. It is reported that "MPs demand tough law on rotten food", together with a licensing system for such companies.

(iv) Terrorism. In the wake of atrocities committed by the IRA and more recently by the Animal Liberation Front, there are repeated calls for tougher and more effective measures to suppress terrorism. It is worthy of note that these extend to calls for an extension of the public international law, notably by creating a new international crime, that of terrorism, seen as a crime against humanity.

(v) Financing students. The projected legal/administrative provision for student loans has attracted fierce criticism.

(vi) Child abuse. In the wake of the Cleveland affair, and the shocking statistics of child abuse which reveal themselves, new and better laws both to protect children and to punish their abusers are called for.

(vii) Fuvenile crime. It is reported that, as a reaction to the growth of juvenile crime, "Government ministers are considering changing the law to make parents responsible for crimes committed by their children."

(viii) Toy food. It is not just the British Parliament which manufactures more and more laws; the EEC is at it too. Now EEC legislation to prohibit the making and sale of 'toy food', (i.e. items intended to be used in play, which simulate real food) is coming into effect.

(ix) Official secrets. The government's Bill ${ }^{2}$ to control the keeping secret of government secrets falls under heavy criticism, even though it is stated to represent a narrowing rather than a broadening of the existing law.

(x) Accidents and disasters. From one writer we learn that responsibility for the list of recent disasters - Piper oil rig, Locherbie, Clapham, M1 air crash - must be laid at the government's door, and that they are ultimately due to the state of the present Health and Safety Laws as enacted in 1974 and administered since. The Health and Safety Inspectors do not have jurisdiction over off-shore oil rigs, nor over railways and transport undertakings. Since 1980 there has been a $19 \%$ decrease in the number of such inspectors. The implication is that if the law was extended to cover such areas and more inspectors employed, these disasters might

2. Now enacted as the Official Secrets Act 1989. 
have been avoided. More laws more vigorously enforced are seen as the remedy for the destruction of aircraft by bombs.

(xi) The atmosphere. Discussion of the 'greenhouse effect', and the release of noxious substances into the lower and upper atmosphere, are now at the top of the agenda. All sorts of responses, each of which involves creating a new legal framework and new regulations, are under consideration. So far as Chlorofluorocarbons or CFCs are concerned, there is talk of an outright ban on their manufacture and use, at least in the developed world, and this would have to be achieved both by international treaty (more international law) and by national legislation. So far as unleaded petrol and the pouring of noxious chemicals and metals into our breathable atmosphere are concerned, the government has attempted up till now to promote the use of unleaded petrol not by reliance on the law, but by the use of the market option on the one hand (manipulating the price mechanism to make unleaded petrol dramatically cheaper than the leaded kind) coupled with resort to the persuasive option. There will surely soon come a time when the UK government will feel itself obliged to use law directly to control pollution of the atmosphere by motor vehicles, by prohibiting the sale of leaded petrol, by requiring the installation of catalytic converters, and so on. More law ... if only the future destruction of the world's ecosystem could be prevented just by law alone, how simple life would be!

(xii) Dog excrement on pavements. This is seen as a health hazard, as well as aesthetically repulsive. The remedy suggested is stronger laws making dog owners absolutely liable, not just to fines, but to clear up the mess themselves.

\section{The reckoning and the overload}

Let us assume for a moment that each and every one of these problems could be met by more and better law (which is a highly debatable proposition). We would still face the problem of juristic overload. Neither the legislative machine, which is overtaxed, nor the agents of the law, whether police, inspectors, registrars, magistrates or health analysts, can take an indefinite increase in their duties and responsibilities. One can observe the overload factor at work even when the law is purportedly simplified. To alleviate the burden on magistrates' courts in administering petty road traffic laws, Parliament introduced simplified methods of dealing with petty road traffic offences, with the issue by police of fixed penalty tickets etc.. Other changes were made in our traffic laws. The effect at the sharp end, that is, in the courts which have to master and administer the new laws and their ancillary procedures, has been to increase still further the already unbearable weight of legislation and administration which presses on them. Magistrates' courts clerks, in particular, have - with every new law which imposes summary penalties or new procedures on bail, advance disclosure, legal aid and the like - to master and hold in their memory this additional information, ready to be produced at the appropriate time.

I select one example among many. The Criminal Justice Act 1988 has just been 
brought into effect. It has major repercussions on the way in which pre-trial and trial procedures are conducted, and its numerous provisions cover a bewildering range of different aspects of the criminal justice system. This has profound implications for the police, prosecutors, legal advisers, and the courts and their staffs. The complexity and range of the Act are sufficiently indicated by the fact that its long title alone, which recites in summary the principal matters covered by the Act, occupies a whole page to itself in the printed copy of the Act which is before me. Consider the implications of these radical changes in the law for those who have to conform to it. For the most part, the Act's provisions are cumulative and not substitutional, that is, they must be added to the already complex burdens which the relevant authorities bear. Each year the pyramid of new laws grows higher and higher. The Criminal Justice Act comprises no fewer than 173 sections and 16 schedules. It is no wonder that C. J. Emmins and G. Scanlan, in their commentary on the Act, ${ }^{3}$ summarise the situation in these terms:-

"It is almost a cliché to remark that the volume and complexity of modern legislation presents [sic] students, practitioners and even judges with almost insoluble problems in trying to keep pace with the speed of change. And yet it is vital that those who will have the task of applying and administering the law in practice become familiar as quickly as possible with the changes that are being made...

... In no area of the law, perhaps, is the speed of change faster or the need to understand and assimilate the changes greater than in the area of the criminal justice system."

And this is in those branches of law, criminal law and procedure, where it is universally agreed that the paramount needs in the interests of justice are for certainty of application and simplicity of operation, if the subjects of the law are to know where they stand.

If it was an official rule that for every new law an old one must be deleted to make way for it, the situation might be controllable. After all, there is a limit to what the machinery can cope with. In my view, that limit has been not merely reached but overrun. What happens then, as with police detection of crime and the enforcement of the criminal law, is that the administrators create their own priority routines. Some offences, accorded the lowest priority, are not pursued or investigated: house burglaries, for instance, or minor motoring offences. A large part of the law is de facto repealed to make way for the new laws.

The examples cited above from the Sunday Times are interesting for another reason. In many of the cases new forms of vicarious responsibility are proposed to ensure that someone pays the penalty for illegal acts. Thus, in the case of pollution, company directors and managers may face penalties - including prison for offences committed by their companies. And parents would face penalties for 
crimes committed by their children, while dog owners would similarly face penalties for the misdeeds of their animals. These proposals will have some interesting consequences, especially if taken with the recurrent and strident calls for a cutting down on the numbers of the present prison population: would this mean that rapists, burglars and muggers would be released from jail to make room for company directors; juveniles left at home while their fathers serve their sentences; and dog owners would wipe away the stain on society left by their dogs by going to jail for non-payment of their dogs' fines? The impact of all this on the notion of individual responsibility for misbehaviour is considerable.

\section{Factors which contribute to the success of laws}

I have already discussed these in detail in my Limits of Law. In bare outline these are as follows:-

Acceptability. It is the continuing acceptance of laws by the law-subjects which aids and strengthens the law. Laws which cut across the grain of society and make new demands on its members have little chance of success, however draconian the penalties attached to secure compliance with them. This is bad news for the new elitists who seek to impose their vision of a better, or a better-organised, society on those who come within their power. The social engineers, who may (as recent British experience so clearly shows) belong either to the Left or the Right of politics, wish to remake society in their own image; it is the annoying resistances of ordinary people which impede this process. Savigny and the historical school of jurisprudence, who emphasize the dominating influence of the Volksgeist (what we might call the national character and traditional mores of a given society) on the pattern of laws in a society, are now generally in disgrace, because they are held to oppose obstacles to the realisation of the new age of compulsory enlightenment. These obstacles are not, however, of their making; and realistic law-givers, who actually wish to secure acceptance and effectiveness of their laws rather than merely to act out their ideological preferences, would do well to recognise this fact.

The seat-belt law poses an interesting question for analysis here. What seems to have happened is that there was what we may call a 'tipping' in the attitudes of drivers to the wearing of seat-belts. Before, one would have said that most drivers would have resented what they would have seen as an interference with their liberties; after, drivers voluntarily took to belting up as a general rule before driving off. Whether this was due to external persuasion, to self-persuasion, or not I cannot tell. Bearing in mind, however, the general disregard of so many other more important traffic laws, one suspects that it was most unlikely to be due to the law itself. There is an interesting comparison with the use of dipped headlights when driving in towns. The law, as it stands at present, does not require drivers to use dipped headlights when driving in towns, though the possibility of having such a rule has been considered. But a law to that effect, if that were now introduced, would as a matter of fact be otiose, because drivers almost invariably have adopted the practice of using dipped headlights when driving in towns at night. No law says 
that they should; the law and practice of other countries may have had some persuasive effect here; perhaps this is an opportunity for a piece of research in what we may term paralegal psychology.

Education. Acceptance largely depends on the people subject to the law acquiring knowledge and understanding of why the behaviour prescribed by the law is advantageous or should be adopted for some other reason, which may be a reason of social morality or justice or prudence. Some laws are themselves educative, and seen to be such. We in England do not go as far as some of the codifiers of Africa, who have accepted that their new laws will not win immediate compliance but who pin their faith on society coming round eventually to accept and follow the new code. One thinks, for instance, of the Ethiopian Civil Code of 1960 , enacted in imperial times, which represented the most advanced legal thinking of its day and interestingly combined features of the French Code civile and English common law - its primary draftsman, the distinguished French comparatist Professor René David, opined that the Code would have little or no immediate influence on behaviour, but might eventually (say, in 100 years!) come into force through a process of education in its aims and provisions.

There is now general agreement that the anti-discrimination laws are of this educational kind. It is not so much the penalties as the attitudes which lie behind them which have sunk into the national consciousness and hence contributed to the modifications of behaviour sought by the law.

Effectiveness of administration. A law which is not applied or effectively administered has little chance of success, unless it corresponds to the way people would behave anyhow. Insufficient thought is often (one might say, usually) given to administration problems until years after the introduction of a new law.

Automaticity of application. This is the ideal to seek for, the self-enforcing law. A law which provides an automatic remedy or penalty is much better than one which depends on human intervention.

Physical rather than legal restraints. Which leads on to our final point: a physical restraint, such as a width gap or a speed ridge in the road, is much more effective than a law, however stringent, in securing compliance. Iron bars are a more effective preventative of burglary than any number of Theft Acts. Consider the failure of legal limits on heavy vehicles in towns as compared with the effectiveness of width pillars which narrow the road; and compare the general failure of the pedestrianisation of streets in London in those cases where no physical barrier is interposed to the movement of vehicles.

\section{Where do we go from here?}

Some people will be profoundly depressed by this analysis, or even tempted to reject it altogether. "After all", they may say, "what alternative is there to law? At least having a law is better than nothing, even if it is ineffective." Having an ineffective law is not better than nothing! It is definitely an inferior option if the only result is contempt for or disregard of the law, and this for two good reasons. 
The first is that unenforced or failed laws weaken, not just themselves, but the whole fabric of legal regulation and the authority of those who propound them; to that extent, ineffective law is a disaster for the civil authority. The second reason is that resort to useless law may inhibit proper effective action of a non-legal character. The trouble is that law is cheap and law is quick; it is so much easier to legislate against sin, crime or other disorder than to rectify the causes of them. One concedes, naturally, that law has a proper place in providing a regulatory framework for effective action: often the civil authority must give itself the power to act.

However, the conclusion is short and brutal. The problems of the planet are not being resolved by law. Reaching for the legal weapon resembles the Bob Hope movie where he draws a pistol in a Wild West saloon, pulls the trigger, and a flag emerges saying 'Bang!' Law should be the last and not the first resort. Lawyers above all others should know from their experience that the legal system is too fragile and ineffective to bear the weights that agitators ("There should be a law about it!") and legislators ("There is a law about it") would like to place on it. Both the civil and the criminal law in this country are now in a state of terminal overload. How nice if - for once - the new edition of a legal textbook could say that it was shorter than its predecessor! Then, at least, we would be progressing in the right direction. 